\title{
DIREITOS DA NATUREZA: BIOCENTRISMO? ${ }^{1}$
}

\section{RIGHTS OF NATURE: BIOCENTRISM?}

Recebido: 12.08.2017

Aprovado: 19.10.2017

Fábio Corrêa Souza de Oliveira*

RESUMO: Este artigo aborda a temática do meio ambiente e desenvolvimento a partir da problematização trazida pela Ética Ambiental, uma filosofia que critica o antropocentrismo. Nesta linha, a perspectiva dos direitos da natureza, previstos pela primeira vez pela Constituição do Equador, enseja controvérsias variadas. Entre elas, se é procedente afirmar que os direitos da natureza representam uma moral biocêntrica. A questão impacta essencialmente o que se entende por desenvolvimento sustentável.

Palavras-chave: Meio Ambiente. Ética Ambiental. Desenvolvimento.

ABSTRACT: This article approaches the theme of the environment and development from the problematization brought by Environmental Ethics, a philosophy that criticizes anthropocentrism. In this line, the perspective of the rights of nature, foreseen for the first time by the Constitution of Ecuador, provokes varied controversies. Among them, it is appropriate to affirm that the rights of nature represent a biocentric morality. The issue essentially impacts on what is meant by sustainable development.

Keywords: Environment. Environmental Ethics. Development.

1 Este artigo foi produzido no conjunto do financiamento fornecido pelo CNPQ ao Centro de Ética Ambiental, da Faculdade de Direito da UFRJ (Edital no 14/2013).

* Professor de Direito Administrativo da Universidade Federal do Rio de Janeiro (UFRJ). Professor do Mestrado e Doutorado em Direito da Universidade Estácio de Sá e Diretor da Pós-Graduação Stricto Sensu em Direito da Faculdade Guanambi/BA. Coordenador do Centro de Ética Ambiental/UFRJ-UFF. Mestre e Doutor em Direito Público pela Universidade do Estado do Rio de Janeiro (UERJ), Pesquisador Visitante na Faculdade de Direito da Universidade de Coimbra (2004, CAPES), Pós-Doutorado em Direito na Universidade Federal de Santa Catarina (UFSC, CNPQ). E-mail: < fabiocsdeoliveira@gmail.com >. 


\section{INTRODUÇÃO}

A produção contemporânea do que se vem a chamar de Ética Ambiental, filosofia que se propõe em rompimento com o antropocentrismo, já contava cerca de um século quando a Constituição do Equador, em 2008, previu, de forma inédita, que a natureza é titular de direitos. Pouco depois, a Lei da Mãe Terra, na Bolívia em 2010, previu o mesmo.

A expressão 'direitos da natureza' não é criação peruana ou boliviana. A expressão, rights of nature, aparece bem antes, é o título de um famoso livro, escrito por Roderick Nash, Professor da Universidade da Califórnia, Santa Bárbara, publicado nos Estados Unidos em 1989: Rights of nature: a history of Environmental Ethics. Integra um movimento que, mais contemporaneamente, passa, entre outros, por Henry Thoreau e John Muir (final do séc. XIX), Rachel Carson e Aldo Leopold (primeira metade do séc. XX) e, mais recentemente, por Arne Naess, George Sessions, Bill Devall, Theodore Roszak, Alan Drengson, Fritjof Capra, James Lovelock e Callicott. Foi nos Estados Unidos que esta perspectiva filosófica ganhou mais espaço na academia e fora dela.

A inédita encampação normativa dos 'direitos da natureza' foi entusiasticamente abraçada por muitos não apenas no Equador e na Bolívia e sim em vários outros lugares e inclusive no Brasil. Muitos passaram a se declarar adeptos da perspectiva, rompidos com o antropocentrismo, defensores da Ética Biocêntrica. O curioso é que tal se deu em maior medida em função do movimento de valorização da cultura ameríndia, que manifestaria tal posição, embora haja dúvida a respeito, mas não em função da compreensão mais cuidadosa da produção da Ética Ambiental antes referida. Sem adentrar propriamente na investigação da Ética Ecocêntrica, do debate com a Ética Animal, e tendo basicamente como referenciais Alberto Acosta e Eduardo Gudynas, se passou a alardear os 'direitos da natureza' como o ponto alto da ruptura com a Ética Antropocêntrica. Então, muitos, não mais doquederepente, sedescobriram não-antropocêntricos ea professaro biocentrismo. Será mesmo? Será que há realmente rompimento com o antropocentrismo? Será que realmente esta visão é biocêntrica?

Ao mesmo tempo em que os direitos da natureza ampliam a titularidade para além dos animais humanos (estes pacificamente considerados sujeitos de direitos) e não-humanos (estes normalmente não considerados titulares de direitos), há uma perda do conceito de direito, um esvaziamento ético e normativo da palavra.

Qual a origem da nomenclatura derechos de la naturaleza? A sua filiação epistemológica? Por que a utilização do vocábulo derechos? Que conteúdo ostenta? Será um mandamento de cunho eminentemente retórico? Uma verborragia constitucional/ legal? Por que admitir que a natureza é titular de direitos mas animais não? Quais os critérios empregados? O que um ente deve ter para ser reconhecido como sujeito de direitos?

O objeto deste estudo é, pois, a contextualização ética dos chamados 'direitos da natureza', nomeadamente a definição da sua filiação filosófica. A metodologia apropriada é a da revisão bibliográfica, notadamente estrangeira, tanto da Europa quanto dos Estados Unidos da América, matrizes da Ética Ambiental, bem como de dois autores sul-americanos, um do Equador e outro do Uruguai, os quais são expoentes na 
defesa dos direitos da natureza. Faz-se também exame da legislação dos dois países que pioneiramente vieram a prever a natureza como titular de direitos: o Equador, o primeiro, que enunciou os derechos de la naturaleza no texto da Constituição, e a Bolívia, com a Lei da Mãe Terra.

Os objetivos gerais convergem em situar a perspectiva dos 'direitos da natureza' na Filosofia, notadamente de acordo com as correntes da Ética Ambiental, bem como saber até que ponto esta concepção se distancia da Ética Antropocêntrica. Os objetivos específicos são concernentes em saber se é procedente afirmar, como se faz amiúde, que a os 'direitos da natureza' traduzem a Ética Biocêntrica.

\section{DIREITOS DA NATUREZA}

Como mencionado, a Constituição do Equador, integrante do novo constitucionalismo latino-americano, trouxe, em mandamento inédito em todo o mundo, a previsão de que a natureza é sujeito de direitos. Reservou um capítulo exclusivamente para os derechos de la naturaleza. O art. 10 não deixa margem de dúvida: "La naturaleza será sujeto de aquellos derechos que le reconozca la Constitución." Mais adiante, a prescrição vem do art. 71, que inaugura o Capítulo Sétimo, Derechos de la naturaleza, do Título II, Derechos: "La naturaleza o Pacha Mama, donde se reproduce y realiza la vida, tiene derecho a que se respete integralmente su existencia y el mantenimiento y regeneración de sus ciclos vitales, estructura, funciones y procesos evolutivos."

Diversos analistas compreendem os direitos da natureza a partir da noção de buen vivir, sumak kawsay (suma qamaña, expressão utilizada pela Constituição da Bolívia), que denota cosmovisão ameríndia, um resgate do saber, da cultura de povos originários do continente, em crítica, contraposição ou diálogo com a (uma) epistemologia eurocêntrica, colonial, moderna. É certo que a conceituação de bem viver abarca diversas idéias e domínios.3 O Capítulo Segundo, Título II, Derechos del buen vivir, art. 14: "Se reconoce el derecho de la población a vivir en un ambiente sano y ecológicamente equilibrado, que garantice la sostenibilidad y el buen vivir, sumak kawsay." Isto é: os seres humanos possuem direito a viver em um ambiente saudável e ecologicamente equilibrado, qualidades que, por sua vez, manifestam direito da própria natureza.

Como registrado, em 2010, na Bolívia, no mesmo sentido da Lei Constitucional do Equador, foi publicada a Ley de Derechos de la Madre Tierra. Define o seu art. 30: "La Madre Tierra es el sistema viviente dinámico conformado por la comunidad indivisible de todos los sistemas de vida y los seres vivos, interrelacionados, interdependientes y complementarios, que comparten un destino común." Entre os direitos listados da Mãe Terra: direito à vida, à diversidade da vida, ao equilibrio, à restauração. A lei elenca deveres perante a Madre Tierra, em síntese: a promoção de uma vida harmônica com a natureza.

Na esfera política equatoriana, nomeadamente ao longo do período constituinte, caso se queira apontar alguém como o maior responsável pela previsão constitucional,

3 Para um inventário: HOUTART, François. El concepto de sumak kawsai (buen vivir) y su correspondencia con el bien comum de la humanidad. Trabajo preparado en el marco del Instituto de Altos Estudios Nacionales (IAEN) para el Ministerio de Relaciones Exteriores del Ecuador, 2011. 
este alguém é Alberto Acosta, Presidente da Assembléia Constituinte, qualificado como político alinhado à esquerda, ecologista. Como afirma Acosta (2011, p. 353), procurando marcar a ruptura com o antropocentrismo, "en los Derechos de la Naturaleza el centro está puesto en la Naturaleza, que incluye por cierto al ser humano. La Naturaleza vale por sí misma, independentemente de la utilidad o de los usos que le dé el ser humano."4

Em fragmento de discurso de Alberto Acosta (2008) quando do exercício constituinte:

[...] la Naturaleza tiene que ser asumida como sujeto de derechos. Derechos de la Naturaleza que deben ser reconocidos a partir de la identidad del ser humano que se encuentra a si mismo en tanto parte de ella. $Y$ desde esta perspectiva amplia e incluyente, el nuevo marco normativo constitucional de nuestro país, en consecuencia, tendría que reconocer que la Naturaleza no es solamente un conjunto de objetos que podrían ser propiedad de alguien, sino también un sujeto propio con derechos legales y con legitimidad procesal.

Na mesma oportunidade, Acosta cita Aldo Leopold, transcrevendo a máxima da Ética da terra, expressando filiação a esta corrente de pensamento. Mas, quem foi Aldo Leopold? O que propugna a Ética da terra?

Aldo Leopold não foi uma liderança ou um pensador sul-americano. Tampouco indígena. Leopold (1887-1948) nasceu e viveu nos Estados Unidos da América, ecologista, caçador, trabalhou no U. S. Forest Service, Professor da Universidade de Wisconsin, foi um precursor do movimento ambientalista. Em 1949 foi publicado o livro A sand county almanac, onde teve lugar um tópico intitulado The land ethic, que se transformou no escrito mais famoso de Leopold (1989). A máxima da Ética da terra: "A thing is rigth when it tends to preserve the integrity, stability, and beauty of the biotic community. It is wrong when it tends otherside." The land ethic tem foco na comunidade biótica, no ecossistema, colocando-se em confrontação com o antropocentrismo. Em outro trecho: "In short, a land ethic changes the role of Homo sapiens from conqueror of the landcommunity to plain member and citizen of it. It implies respect for his fellow-members, and also respect for the community as such. (1989, p. 204).

Muito embora a menção ao respeito devido aos membros da comunidade (animais, plantas, e.g.), a Ética da terra é uma Ética Ecocêntrica, ou seja, voltada para a coletividade e não para os indivíduos. Investe, por exemplo, contra a extinção de/das espécies de animais mas não propriamente contra a morte dos animais individualmente considerados. Por outras palavras: seria mais grave matar uma onça, espécie em risco de extinção, do que matar um pato ou um castor desde que abundantes. Isto é: o valor do indivíduo não é dado por ele próprio e sim pelo pertencimento a uma espécie, seu valor, portanto, não é intrínseco e sim dado em função do todo, do ecossistema, é valor coletivizado ou relativizado em razão da espécie.

\footnotetext{
4 Em continuidade, traduz o autor: "Esto es lo que representa una visión biocéntrica." Talvez melhor fosse dizer, ao invés de biocêntrica, ecocêntrica, como se verá adiante. Trata-se de um biocentrismo ecológico ou coletivista. Mais adiante se volta à questão. ACOSTA, Alberto. Los derechos de la naturaleza: una lectura sobre el derecho a la existência. In: La naturaleza con derechos: de la Filosofía a la Política. (Orgs. Alberto Acosta e Esperanza Martínez) Quito: Abya-Yala, p. 317-369, 2011, p. 353. Acosta também utiliza como sinônima a expressão direitos ecológicos.
} 
Um interlocutor destacado de Alberto Acosta, Eduardo Gudynas (2010, p. 52), do Centro Latino Americano de Ecología Social, Uruguai, assinala esta corrente como fundamentadora da constitucionalização dos direitos da natureza: "El reconocimiento ecuatoriano de los derechos de la Naturaleza mantuvo conexiones intermitentes con los aportes académicos, en especial aquel en el hemisferio norte”. Afirmando-se na defesa da concepção biocêntrica, tanto Alberto Acosta quanto Eduardo Gudynas aludem à Ecologia Profunda. O termo Deep Ecology foi cunhado, em 1972, por Arne Naess, Professor de Filosofia da Universidade de Oslo. ${ }^{5}$

\section{BIOCENTRISMO?}

É muito comum a associação entre direitos da natureza e Ética Biocêntrica. Como anotado, Acosta e Gudynas e inclusive vários autores brasileiros fazem tal conjugação. Os direitos da natureza seriam expressão do biocentrismo. Será mesmo?

Responder a esta pergunta exige definir o que é biocentrismo. O termo é tomado com significações distintas ou ainda com implicações diferentes, o que gera pouca clareza e confusão. A Ética Biocêntrica é aquela centrada na vida independente de categorizações, abrange todos os seres vivos, expandindo, portanto, para além do critério da senciência, ${ }^{6}$ de maneira a asseverar que todo vivente tem valor em si, intrínseco/inerente, ${ }^{7}$ e não

5 O texto paradigmático, publicado no ano seguinte, foi The Shallow and the Deep, Long-Range Ecology Movement: a summary. Pode ser encontrado em: DRENGSON, Alan; INOUE, Yuichi. The Deep Ecology Movement: an introductory anthology. (Orgs.) Berkeley, California: North Atlantic Books, 1995. Em 1984, Arne Naess e George Sessions expuseram um elenco de 8 pontos como identificador da Plataforma Comum da Ecologia Profunda (Basic Principles of Deep Ecology). São estes: "1. The well-being and flourishing of human and non-human life on Earth have value in themselves. These values are independent of the usefulness of the non-human world for human purposes. 2. Richness and diversity of life forms contribute to the realization of these values and are also values in themselves. 3. Humans have no right to reduce this richness and diversity except to satisfy vital needs. 4. The flourishing of human life and cultures is compatible with a substantial decrease of the human population. The flourishing of nonhuman life requires such a decrease. 5. Present human interference with the non-human world is excessive, and the situation is rapidly worsening. 6 . Policies must therefore be changed. The changes in policies affect basic economic, technological, and ideological structures. The resulting state of affairs will be deeply different from the present. 7 . The ideological change is mainly that of appreciating quality (dwelling in situations of inherent worth) rather than adhering to an increasingly higher standard of living. There will be a profound awareness of the difference between big and great. 8. Those who subscribe to the foregoing points have an obligation directly or indirectly to participate in the attempt to implement the necessary changes." V. DRENGSON, Alan; DEVALL, Bill (Orgs.). The Ecology of Wisdom: writings by Arne Naess. Berkeley: Counterpoint, 2010, p. 111 e 112. Tb. DEVALL, Bill; SESSIONS, George. Deep Ecology: living as if nature mattered. Salt Lake City: Peregrine Smith Book, 1985, p. 69-73. Naess salienta que a Plataforma Comum da Ecologia Profunda pode encontrar base em diferentes concepções filosóficas, inclusive religiosas. Naess e Devall, por exemplo, declararam filiação ao budismo. Apesar de Naess assinalar que o cristianismo pode fundamentar a Plataforma Comum, fato é que isto, se possível, não se dá sem traumas, sem abrir mão ou rever postulados centrais que identificam a religião cristã. V. OLIVEIRA, Fábio Corrêa Souza de. Especismo religioso. In: Revista Brasileira de Direito Animal, n. 8. Salvador: Evolução, p. 161-220, 2011.

6 Embora subsista uma discussão sobre a definição de senciência e, também por isso, quais seres são ou não sencientes (uma fronteira vacilante, nas palavras de Carlos Naconecy), pode-se dizer que senciente é o ser capaz de sofrer, sentir dor física ou abalo psicológico, bem como de se perceber enquanto indivíduo e ter um entendimento acerca do seu meio, de buscar seu bem-estar, conforto, felicidade. Este conceito abarca uma definição de consciência, esta também objeto de debate. NACONECY, Carlos. Ética animal... Ou uma ética para vertebrados.? Um animalista também pratica especismo? In: Revista Brasileira de Direito Animal, n. 3. Salvador: Evolução, p. 119-153, 2007.

7 Os termos são aqui utilizados sem distinção. Enquanto Tom Regan distingue valor intrínseco de valor inerente, Arne Naess, como registrado à frente, emprega as expressões como sinônimas. Utiliza-se a nomenclatura valor intrínseco com o mesmo conceito que Regan empresta à expressão valor inerente. É o mesmo significado de Arne Naess. REGAN, Tom. The case for animal rights. University of California, 2008, p. 235-239. 
mero valor instrumental. "The deep ecology movement principles specifically emphasize respect for the intrinsic worth of all beings (from microbes to elephants and humans)", sublinha Alan Drengson (2010, p. 27).

Arne Naess, que foi, em muitos aspectos, inclusive nucleares, mais sugestivo do que conclusivo, foi reiteradamente questionado acerca da significação exata do termo intrinsic value (inherent value, value in itself) e não se preocupou tanto em desenvolver a categoria, núcleo do rompimento com a Ecologia Rasa, embora tenha ressalvado que o nível "of vagueness and ambiguity must be within tolerable limits". (NAESS, 1995, p. 216 e 217).

Naess chegou a negar a interpretação do seu pensamento como valorizador do das espécies em detrimento dos indivíduos. Veja-se: "I try in my ecosophy to be consistente in my view that individual beings, and only individual beings, can have inherent value, and not classes of individuals as such." (NAESS, 1995, p. 217). O ponto, salienta Naess, a saber é "iflandscapes, or the whole Earth, are not taken to be individuals beings, and not classes of individual beings." 9 (1995, p. 217)

Os direitos da natureza são claramente expressão da Ética Ecocêntrica. A rigor, não traduzem a Ética Biocêntrica. A Ética Biocêntrica é individualista. Uma vez que o seu critério de fundamentação é a vida, todo ser vivo é valorizado por si, individualmente portanto. Como o nome revela, a Ética Ecocêntrica, diferentemente, está fiada no ecossistema, no todo e não no indivíduo, é holista. $O$ valor da vida é medido em razão do que o ser representa para o conjunto biótico. É, pois, valor instrumental e não valor intrínseco. E não se diga que a separação não é procedente porque "a parte está no todo e o todo está na parte”. Isto é falsear o problema e tratar a questão com pouca reflexão ou seriedade.

Afirmar que todo ser vivo tem valor intrínseco demanda esclarecer quais as consequências daí decorrentes. A começar por responder se todo o ser vivo tem o mesmo valor: uma formiga, um elefante, uma ameba, uma samambaia, um humano, uma amendoeira, uma águia, um porco, uma flor. Caso a resposta seja negativa, alguns têm mais valor (intrínseco) do que outros? Qual o critério para estabelecer o escalonamento? Se o critério é tão apenas a vida, não haveria, obviamente, outro critério.

No campo da espécie humana, o reconhecimento do valor intrínseco de todos os seres humanos recebeu o nome de dignidade. Esta a lição, entre outros, de Kant: o ser humano não pode ser reduzido a meio para o atendimento de interesse de outro ser humano. Da dignidade humana foram derivados os direitos: à vida, à liberdade, à integridade física, entre outros.

8 No texto The basics of the Deep Ecology Movement, esclareceu, em relação ao ponto ㄲo 1 da Common Platform of Deep Ecology: "The term life is used here in a comprehensive, nontechnical way to refer also to what biologists classify as nonliving: rivers (watersheds), landscapes, cultures, ecosystems, the living earth." NAESS, Arne. The basics of the Deep Ecology Movement. In: The Ecology of Wisdom: writings by Arne Naess, cit., p. 105-119, p. 112.

9 Esta é a abertura para o Ecocentrismo. Apesar da afirmação de Naess, uma ética individualista, focada, pois, no indivíduo singularmente considerado, como nos casos de Peter Singer e Tom Regan, não encampa coletividades como indivíduos. Um ecossistema não tem interesses a serem levados em conta, na teoria de Singer, e nem é sujeito de direitos (sujeito-de-uma-vida), consonante a doutrina de Regan. 
Ora, os direitos da natureza são direitos de uma coletividade abstrata, da qual não se sabe a rigor quem pertence, onde começa e termina, quais as suas demarcações. Afinal, de que natureza se está a falar? Um rio? Uma lagoa? Uma floresta? O serrado? O oceano? Ora, o planeta é, em si, um ecossistema, a Hipótese de Gaia, de Lovelock. Seja como for, direitos da natureza são direitos ecossistêmicos.

A leitura do texto constitucional equatoriano não deixa dúvida quanto à filiação ao ecocentrismo. Em nenhuma passagem assenta que indivíduos não-humanos são sujeitos de direito. Tão somente a natureza é titular de direitos. O que se busca proteger são seus ciclos vitais, estrutura, função e processos evolutivos. Alberto Acosta não deixa dúvida ao explicar a percepção de esteio da constitucionalização dos direitos da natureza (e o mesmo se pode afirmar para a lei boliviana): "Estos derechos defienden el mantenimiento de los sistemas de vida, los conjuntos de vida. Su atención se fija en los ecosistemas, en las colectividades, no en los individuos." (ACOSTA, 2011, p. 353).

$\mathrm{O}$ art. 73 da Carta Constitucional do Equador é também emblemático: "EI Estado aplicará medidas de precaución y restricción para las actividades que puedan conducir a la extinción de especies, la destrucción de ecosistemas o la alteración permanente de los ciclos naturales." Notadamente claro a respeito é o art. $5^{\mathbf{0}}$ da Lei da Mãe Terra, que configura a Mãe Terra como sujeito coletivo de interesse publico. A conceituação do direito à vida, enquanto direito da natureza, é igualmente reveladora (art. $7^{\mathbf{0}}, \mathbf{1}$ ): “Es el derecho al mantenimiento de la integridad de los sistemas de vida y los procesos naturales que los sustentan, así como las capacidades y condiciones para su regeneración.” É, pois, o direito à vida de uma coletividade, não de um ser especificamente, em si mesmo.

Mas, para além desta problemática, os direitos da natureza enfrentam outro problema. O significado da palavra direito. O que significa afirmar que a natureza tem direito à vida? Afirmar que a natureza tem direito aos seus ciclos vitais? Seria possível construir uma usina hidroelétrica? Porque o ciclo vital foi alterado e não irá mais se recompor, ao menos não como antes. É possível dragar um rio? Fazer um aterro?

Um direito (interesse) só cede legitimamente diante de outro direito (interesse) equivalente ou de um direito (interesse) considerado superior. A legítima defesa autoriza a perda da vida do agressor em prol da vida do agredido. O estado de necessidade justifica que, em salvaguarda da própria vida, a vida de outro possa perecer. É o mesmo direito em disputa: direito à vida $x$ direito à vida. Não é aceitável, em nome do direito à liberdade de expressão, desconsiderar o direito à privacidade para fotografar os recônditos da vida sexual de alguém. Não é permitido, em nome do direito de propriedade, matar o criminoso que acabou de cometer um furto.

O que se quer registrar é: tendo em vista que uma árvore tem valor intrínseco, é moralmente aceitável derrubá-la para fazer objetos de decoração? Os bens não são, em tese, equivalentes. $\mathrm{O}$ direito à vida da árvore, seu valor inerente, versus o interesse de fazer objetos de madeira para enfeito, valor instrumental da árvore. Caso se admita o corte da árvore por tal motivo, a noção de valor intrínseco se esfumaça, assim como fica degradada a tese de que a árvore tem direito à vida. Somente seria cabível derrubar uma árvore se ela estivesse ameaçando outra vida (a minha, a de outra árvore). 
Acontece que a Ecologia Profunda afirma que todos os seres vivos ostentam the equal right to live and blossom. O igual direito de viver e florescer não conhece, portanto, fronteira pela senciência. É o biospherical egalitarianism: bactérias, estrelas-do-mar, carvalhos, ervas-daninhas, lesmas. Em tese, qualquer planta tem tanto direito à vida quanto qualquer animal e, ademais, a morte de uns por outros na luta pela vida, conforme os contornos da cadeia trófica, é natural, inescapável (DEVALL; SESSIONS, 2001, p. 6768)..$^{10}$ Será que esta é mesmo a melhor compreensão ética?

\section{POR QUE DIREITOS DA NATUREZA E NÃO DIREITOS DOS ANIMAIS?}

A quem defende que a natureza deve ser percebida como titular de direitos se pode indagar por qual razão animais (não-humanos) não? Ora, animais reúnem um conjunto de qualidades afinadas ao reconhecimento de direitos, na mesma linha do que acontece com seres humanos, qualidades que não estão presentes na natureza, a qual, sendo uma reunião de indivíduos, não é propriamente um indivíduo, não é comparável a um ser humano, a um cachorro ou a uma baleia.

O que Acosta e Gudynas fazem é afirmar que a natureza tem valor próprio e atribuir a ela direitos (embora claramente com uma densidade jurídica menor do que aquela ostentada pelos direitos titularizados pelos humanos). Ora, sustentar que a natureza (a coletividade, o bioma) tem direito à vida é muito diverso de sustentar que um ser humano tem direito à vida. As consequências das duas assertivas são diferentes. Eles também afirmam que, para além da natureza, todos os seres vivos têm valor intrínseco - como antes afirmaram também, e. g., Arne Naess e Alan Drengson -, porém não chegam ao mesmo ponto, ou seja, não utilizam a palavra direitos para os animais. Isto é: a natureza tem valor intrínseco e, por consequência, tem direitos; animais também têm valor intrínseco mas não tem direitos. Por que não?

Todavia, conforme registrado, Naess escreveu que todos os seres vivos possuem the equal right to live and blossom. O que significa exatamente, em termos éticos e jurídicos responsáveis, proclamar isto?

Apesar de dizer que todos têm igual direito à vida, ecocentristas não pensam ser um problema moral matar animais para consumo: comida, vestuário. Alberto Acosta e Eduardo Gudynas, conquanto proclamem o valor intrínseco de todos os seres vivos, são expressos em registrar que os direitos da natureza não impedem a ganadería (pecuária) ou a pesca. (GUDYNAS, 2010, p. 66; ACOSTA, 2011, p. 354). Nesta esteira, quando se postula el respeto al valor intrínseco de todo ser viviente não significa que se concorda com a tese, da Ética Animal/do Direito dos Animais, de que seres humanos devem, por exemplo, adotar a dieta vegetariana e não utilizar roupas produzidas com peles de animais. Por outras palavras: o respeito ao valor intrínseco de todo ser vivo não obstaculiza que possamos comê-los regularmente, por meio da pesca, da pecuária, criação e abate de

1o Bill Devall e George Sessions escrevem: "Mutual predation is a biological fact of life, and many of the world's religions have struggled with the spiritual implications of this. Some animal liberationists who attempt to side-step this problem by advocating vegetarianism are forced to say that the entire plant kingdom including rain forests have no right to their own existence. This evasion flies in the face of the basic intuition of equality." Deep ecology: living as if nature mattered, cit. 
suínos, galináceos e outros animais.

Mas, então, sejamos francos e precisos: qual a importância de se afirmar que o animal tem valor intrínseco? Eu posso usar seu corpo, vestir a sua pele por mero gosto estético, comer a sua carne por mero deleite do paladar, mas continuo afirmando que este ser possui valor intrínseco? É uma farsa, não? Uma verborragia, uma retórica vazia. É razoável dizer que todo o ser humano tem valor intrínseco, mas praticar a escravidão humana? Tem sentido enunciar que uma mulher tem valor intrínseco, mas admitir o estupro? Seres humanos têm valor inerente, então posso comê-los? Posso usar as suas peles? Por que não? Afinal, qual o significado da biocentric equality? Uns possuem mais valor intrínseco do que outros? Na frase de George Orwell, em A revolução dos bichos: "Os animais são todos iguais, mas uns são mais iguais do que outros".

Registre-se que a citada igualdade biocêntrica dá ensejo à tese de que não há razão para se adotar a alimentação vegetariana porque nesta dieta seres vivos são mortos, os vegetais, e, assim, a dieta carnívora é tão autorizada quanto a outra. Sejamos francos mais uma vez: o que se está a sustentar é que sangrar um porco é o mesmo que arrancar uma cenoura? Que matar um boi é o mesmo que cortar um pé de alface? Cortar um galho de uma árvore e a pata de um cavalo é igual? Se a resposta surpreendente for sim, então por qual motivo não fazer o mesmo com os seres humanos? Matar um humano, uma galinha ou tirar uma batata da terra é idêntico, não?

Ecocentristas não comem carne humana, mas comem carnes de animais. Diante da assertiva de que uma vaca possui direito à vida tal como um ser humano e, ao mesmo tempo, da admissibilidade de matá-la para satisfazer o paladar, Regan conclama os ecocentristas to take rights seriously. (REGAN, 2008, p. 362) Afinal de contas, de que direito à vida se está a falar? Um direito que não protege seu titular contra uma mera preferência alheia que põe termo à sua vida? Ora, isso não é um direito. É a perversão do termo direito. É um engodo.

Porém, supreendentemente, Arne Naess (1995, p. 223) assegura não estar de acordo também com gradações, o direito a viver e prosperar é o mesmo para todos:

If we speak of diferences in the rights or value we do not speak of the rights or value I have in mind. It is not meaningful to speak of degrees of intrinsic or inherent value when speaking of the right of individuals to live and blossom.

A passagem transcrita gera realmente um aturdimento. Ilustra-se com caso narrado pelo próprio Naess. Conta Naess que, durante os anos em que viveu nas altas montanhas da Noruega, se viu continuamente forçado a pisar em uma espécie de planta local, a Salix herbacea. Nada obstante, aduz que nunca tentou justificar o fato com o pensamento de que tais plantas possuem um direito à vida e a prosperar ou um valor intrínseco inferior ao de outros seres vivos ou ao dele próprio. Esclarece Naess (1995, p. 223): "What I have done here is to try to verbalize an intuition." Sem embargo, "if there is a choice concerning whether to step on a Salix herbacea, rather than on the small, more overwhelmingly beatiful and rarer Gentiana nivalis, I unhesitatingly and deliberately step on the former." (NAESS, 1995, p. 223) Ora, Naess não está a se contradizer? Todos os seres têm o mesmo direito à vida e a florescer? Mas a escolha de Naess não estabeleceu uma 
hierarquia? Não concluiu que a vida da Gentiana nivalis vale mais do que a vida da Salix herbacea? Este é um bom critério, universalizável para seres humanos inclusive? Beleza e raridade?

Naess propõe a adoção de dois critérios para operar interesses em conflito: vitalness e nearness: "The greater vital interest has priority over the less vital. And the near has priority over the more remote - in space, time, culture, and species." (NAESS, 1995, p. 222) Continua o autor: "Nearness derives its priority from our special responsibilities, obligations, and insights as humans among humans." (NAESS, 1995, p. 223) O critério nearness não transmite uma suspeita ou uma aproximação ao antropocentrismo? Explicar o consumo de suínos mas não o de humanos em razão do critério nearness não é titubear ou cair no antropocentrismo que tanto se quer afastar? É tal critério que explicaria comer vaca e não cavalo ou cachorro? O cachorro é mais próximo (dos humanos) do que o frango? Mas aqui há um componente cultural. Na China, como se sabe, comer cachorro não é propriamente chocante. Então, a teoria é relativista: come-se aqui, não se come lá. De todo modo, resta a interrogação: por que existiria necessariamente mais proximidade entre seres humanos? Eu não poderia ter mais afinidade, mais afetividade, mais proximidade com animais (cães, gatos e outros) do que com seres humanos? Isto me autorizaria a comer seres humanos?

Nada obstante, o critério vitalness, a ser levado a sério, não parece levar a que o interesse humano por degustar carne de frango justifique matar o animal, uma vez que nem mesmo o conflito se dá entre dois interesses vitais, mas sim entre uma preferência e um interesse vital, talvez o mais forte de todos, qual seja, o de permanecer vivo. Porém, Naess não faz a defesa do vegetarianismo."

O Direito dos Animais não emprega a expressão direito no mesmo sentido de Arne Naess, Acosta ou Gudynas. Dizer que os animais têm direito à vida importa dizer que os seres humanos não podem matá-los a não ser em legítima defesa ou estado de necessidade, além de poderem ter para com eles dever de agir.

A preocupação de Alberto Acosta é com o bem-estar dos animais, condena a crueldade, os maus-tratos, a experimentação cruel com animais, a utilização agressiva de hormônios, la existencia de mataderos en condiciones deplorables ou as touradas. ${ }^{12}$ No mesmo sentido, Gudynas propõe outra pecuária. (GUDYNAS, 2010, p. 66). Traduzindo: el respeto al valor intrínseco de todo ser viviente se traduz em um bem-estarismo, o que

\footnotetext{
11 A lógica de Naess se afigura sobretudo Ecocêntrica. Repare-se no trecho a seguir: "the use of threatened species for food or fur clothing may be more or less vital for certain poor families in non-industrial human communities. But for people who are not poor, such use is clearly ecologically irresponsible.” Idem. A irresponsabilidade é ecológica e não com o indivíduo.

12 "El trato cruel, el abuso y la muerte de animales son síntomas de una ruptura de nuestra condición de seres que integramos la naturaleza. Nadie tiene derecho a maltratar a otras especies, a abusar de ellas, a pretenderse con derecho a dominar y maltratar. Nuestra condición de ser parte de la Pachamama es una ruta de un nuevo aprendizaje que los pueblos andinos comparten con el conjunto de las sociedades. Esta aproximación replantea prácticas culturales propias y nos invita a cuestionar otras, incluso algunas calificadas como ciencia, por ejemplo la experimentación cruel con animales, $u$ otras de producción y consumo, como la cría masiva de animales en condiciones de irrespeto total a la calidad de vida, o la existencia de mataderos em condiciones deplorables, o incluso el agressivo uso de productos como son las hormonas... y por supuesto, las corridas de toros." ACOSTA, Alberto. Los derechos de la naturaleza: una lectura sobre el derecho a la existência, cit., p. 371 e 372.
} 
está muito aquém da plataforma dos direitos dos animais ou dos direitos humanos. Repita-se: a vaca não tem direito à vida diante da vontade humana de comê-la. $\mathrm{O}$ valor intrínseco da vaca a protege apenas de maus-tratos.

Em que pese Acosta e Gudynas afirmarem que os direitos da natureza não impedem a pecuária ou a pesca - tendo em conta que a pecuária é, v.g., o maior vetor de devastação da floresta amazônica, além de contribuir para o efeito estufa (gás metano), a degradação ambiental; ${ }^{13}$ haja vista a queda vertiginosa do número de peixes, inclusive com a extinção local ou global de espécies, sem que os ciclos vitais consigam, pois, repor o número da população, é fenômeno cada vez mais presente, já que o consumo humano supera a capacidade de reposição do ecossistema marinho,$-{ }^{14}$ a legitimidade ecocêntrica de tais práticas é bastante contestável.

É possível afirmar que a concepção de valor intrínseco no campo da Ética Animal/ do Direito dos Animais é bem mais robusta do que a noção que a mesma expressão enverga na dimensão filosófica que embala os direitos da natureza. Dizer, como fazem os ecologistas, que um porco tem interesse/direito de viver significa tão somente que ele quer viver, que esta vontade/impulso deve ser, em alguma medida, levada em conta, mas não ao ponto de impedir que ele seja morto a fim de comer seu corpo ou fazer da sua pele roupa. Não o nivela, ao contrário do que a biocentric equality parece sugerir, com o humano: o direito à vida do porco não importa em que ele não possa ser morto a não ser em legítima defesa ou estado de necessidade, como acontece entre seres humanos.

Arne Naess, ao enunciar uma lista de tendências e atitudes que caracterizam os adeptos do Movimento da Ecologia Profunda, registra que o vegetarianismo total ou parcial é compatível com a Ecologia Profunda, lifestyle. Naess, conquanto não defenda a Ética Animal não a afasta, por incompatibilidade, da Ecologia Profunda. Todavia, a dissonância é flagrante. A Ética Animal não propugna simplesmente um estilo de vida entendido como algo pessoal, opcional. A Ética Animal defende uma plataforma deontológica, um imperativo moral, o que deve ser feito (e não o que pode ser feito). O vegetarianismo não é uma escolha de cada um, tal como exposto por Naess, é uma obrigação moral, uma determinação de justiça. Ademais, reitere-se, a Ética Animal é individualista e não ecocêntrica. Logo, a rigor, a Ética Ecocêntrica (os direitos da natureza) e a Ética Animal são, assim, incompatíveis sim.

Arne Naess considera a pergunta "Why can't animals have rights?" como uma

13 A farra do boi na Amazônia. Greenpeace Brasil. Junho de 2009. www.greenpeace.org.br O nocivo resultado ecológico da pecuária (mas também das grandes monoculturas, dos agrotóxicos, etc.) é reconhecido pelos Estados, inclusive pelo Brasil. Também pela ONU/PNUMA, em vários documentos.

14 "Por exemplo: atualmente, apenas 20\% das reservas populacionais de peixes comerciais, em sua maioria de espécies de baixo preço, são subexploradas; $52 \%$ são totalmente exploradas sem mais espaço para expansão; cerca de $20 \%$ são sobreexploradas e $8 \%$ estão esgotadas. A água está se tornando escassa e há previsão de que o estresse hídrico aumente quando a distribuição de água satisfizer apenas $60 \%$ da demanda mundial em 20 anos. A agricultura teve um aumento de colheitas devido, essencialmente, ao uso de fertilizantes químicos, que reduziram a qualidade do solo e não refrearam a tendência crescente de desmatamento (que continua a 13 milhões de hectares de floresta por ano de 1990-2005). A escassez ecológica está, portanto, afetando seriamente a gama inteira de setores econômicos, que são o alicerce do fornecimento alimentar humano (pesca, agricultura, água doce, silvicultura) e uma fonte crítica de sustento para a população carente. A escassez ecológica e a desigualdade social são marcas registradas de uma economia que está longe de se tornar 'verde’” Rumo a uma economia verde: caminhos para o desenvolvimento sustentável e a erradicação da pobreza, Programa das Nações Unidas para o Desenvolvimento (PNUMA, 2011). 
good question. Todavia, infelizmente (embora, estrategicamente), não desenvolve a abordagem. Acosta, Gudynas e os adeptos dos direitos da natureza poderiam tentar respondê-la.

\section{CONCLUSÃO}

Bem observada, a tese dos direitos da natureza é antes ecocêntrica do que biocêntrica. No discurso dos direitos da natureza há um apelo à harmonização com a natureza. Mas, harmonização com quem exatamente? Qual harmonia pode haver se está autorizado matar animais para satisfazer ao paladar ou para vestimentas e outros utensílios? Há que respeitar a natureza, se alardeia. Matar animais por essas razões e ao mesmo tempo respeitá-los é possível? Usar animais para transporte, como a carregar cargas na trilha para Machu Picchu, é demonstração de respeito? A pescaria é a imagem idílica de uma vida em harmonia com a natureza?

Mesmo na vertente dos direitos da natureza, o antropocentrismo não está superado, pois permanecem as perguntas por qual motivo somente os seres humanos seriam, singularmente, titulares de direitos? Por qual razão apenas reconhecer, fora da humanidade, um sujeito de direitos que seja coletivo? Por que uma leoa, um condor, um jacaré, um tubarão ou chimpanzé não seriam sujeitos de direito? Enfim: qual a fundamentação que explica admitir que cada ser humano, todos também integrantes da natureza, é sujeito de direito e negar o mesmo para cada animal não-humano (deixando de lado por ora [exclusivamente em função da linha argumentativa deste trabalho] a discussão da senciência e, assim, a questão de reconhecer titulares individuais de direitos para além da animalidade)?

Se não é certo convergir todos os humanos em uma coletividade para efeito de tê-la, apenas ela, como sujeito de direito, não é certo também para os animais. Fundir todos os animais na Pachamama é um totalitarismo coletivista, fazendo que os rostos se esvaneçam, que as subjetividades não se divisem, em prol de uma coletividade que não os tem enquanto seres individuais, capitulando a uma instrumentalização, a um utilitarismo, tudo mais conveniente a interesses humanos do que admitir que cada animal possui direitos.

É mais palatável para o gosto geral dizer que os Andes têm direito à manutenção do seu ecossistema, da sua biodiversidade, do que dizer que os animais têm direito à liberdade e por isto não podem ser trancafiados em gaiolas ou jaulas. É menos estranho defender que um cão possui direitos do que a tese de que um rio possui direitos. É mais fácil ser contra a mercantilização da natureza, a privatização da água, defender la eliminación de critérios mercantiles para utilizar los servicios ambientales (Acosta), do que ser contra a comercialização de animais (um dos mais rentáveis do mundo), do que defender que animais não são propriedades. É menos problemático sustentar que o Rio São Francisco não deve ser contaminado do que sustentar que os animais não devem sofrer experimentações, vivissecção, ainda que tais experimentos tragam proveito para demandas humanas. Mais fácil aceitar que a Floresta Amazônica tem direito ao seu ciclo natural, ao seu bioma, do que aceitar que os animais têm direito aos seus corpos. Com 
menor resistência se depara a assertiva de que não se deve derrubar mais árvores de paubrasil do que a assertiva de que não se deve continuar a matar animais para alimentação, salvo estado de necessidade. Mais provável convencer de que é preciso proteger os ursos pandas em função da ameaça de extinção do que convencer a não matar frangos ou porcos, multiplicados e criados aos milhares para comida.

Sem dúvida, a pauta dos direitos da natureza é menos extravagante, exótica, menos conflituosa com a cultura humana tradicional, seus interesses, do que os direitos dos animais. É, segundo o senso comum, mais admissível dizer, como faz Alberto Acosta, que "los Derechos Humanos se complementan con los Derechos de la Naturaleza, y viceversa" do que dizer que os direitos humanos se complementam com os direitos dos animais e vice-versa.

O reconhecimento de que seres humanos possuem valor intrínseco levou ao reconhecimento de direitos humanos, como o direito à vida, à integridade física e à liberdade. Se animais também têm valor intrínseco, como Naess, Acosta e Gudynas afirmam, deveriam ter também direitos, como o direito à vida, à integridade física e à liberdade.

Alberto Acosta e Eduardo Gudynas e aqueles que perfilham a perspectiva dos direitos da natureza devem procurar oferecer uma boa resposta para a indagação formulada por Arne Naess: "Why can't animals have rights?" Naess não encontrou uma boa resposta para infirmar a compreensão de que animais têm direitos ou, conforme expõe Peter Singer, de que deve ser aplicado o princípio da igual consideração de interesses. Naess não respondeu. E nem Acosta ou Gudynas.

\section{REFERÊNCIAS}

ACOSTA, Alberto. La naturaleza como sujeto de derechos. Asamblea Nacional Constituyente del Ecuador, 29 de fevereiro de 2008. Reproduzido no Semanario Peripecias, no 87, 5 mar. 2008.

Los derechos de la naturaleza: una lectura sobre el derecho a la existência. In: La naturaleza con derechos: de la Filosofía a la Política. (Orgs. Alberto Acosta e Esperanza Martínez) Quito: Abya-Yala, p. 317-369, 2011.

ACOSTA, Alberto; MARTÍNEZ, Esperanza (Orgs.). La naturaleza con derechos: de la Filosofía a la Política. Quito: Abya-Yala, 2011.

DEVALL, Bill. The deep, long-range ecology movement 1960-20oo: a review. In: Ethics \& the environment, 6.1. Indiana University Press, p. 18-41, 2001.

; DRENGSON, Alan (Orgs.). The ecology of wisdom: writings by Arne Naess. Berkeley: Counterpoint, 2010. 
; SESSIONS, George. Deep Ecology: living as if nature mattered. Salt Lake City: Peregrine Smith Book, 1985.

DRENGSON, Alan. Introduction. The life and work of Arne Naess: an appreciative overview by Alan Drengson. In: The Ecology of Wisdom: writings by Arne Naess. (Orgs. Bill Devall e Alan Drengson) Berkeley: Counterpoint, p. 3-41, 2010.

; INOUE, Yuichi (Orgs.). The deep ecology movement: an introductory anthology. Berkeley, California: North Atlantic Books, 1995.

GUDYNAS, Eduardo. La senda biocéntrica: valores intrínsecos, derechos de la naturaleza y justicia ecológica. Tabula Rasa, № 13. Bogotá, Colômbia, p. 45-71, 2010

HOUTART, François. Elconceptodesumak kawsai (buenvivir) ysu correspondencia con el bien comum de la humanidad. Trabajo preparado en el marco del Instituto de Altos Estudios Nacionales (IAEN) para el Ministerio de Relaciones Exteriores del Ecuador, 2011.

LEOPOLD. Aldo. A sand county almanac: and sketches here and there. Oxford University Press, 1989.

LOURENÇO, Daniel Braga. Direito dos animais: fundamentação e novas perspectivas. Porto Alegre: Sergio Antonio Fabris, 2008.

; OLIVEIRA, Fábio Corrêa Souza de. Em prol do direito dos animais: inventário, titularidade e categorias. In: Juris Poiesis, Revista do mestrado e doutorado em direito da universidade Estácio de Sá. Ano 12, № 12, p. 113-157, 2009.

. Sustentabilidade; economia verde; direito dos animais; ecologia profunda: algumas considerações. In: Revista do Instituto do Direito Brasileiro. N. 1. Faculdade de Direito da Universidade de Lisboa, p. 365-404, 2012.

Sustentabilidade insustentável? In: A sustentabilidade ambiental em suas múltiplas faces. Campinas: Milenium, p. 297-318, 2012.

NACONECY, Carlos. Ética animal... Ou uma ética para vertebrados.? Um animalista também pratica especismo? In: Revista Brasileira de Direito Animal, n. 3. Salvador: Evolução, p. 119-153, 2007.

NAESS. Arne. Equality, sameness, and rights. In: Deep Ecology for the twenty-first century. (Org. George Sessions) Boston, Londres: Shambhala, p. 222-224, 1995. 
The basics of the Deep Ecology Movement. In: The ecology of wisdom: writings by Arne Naess. (Orgs. Bill Devall e Alan Drengson) Berkeley: Counterpoint, p. 105-119, 2010.

. The Deep Ecology 'Eight Points' revisited. In: Deep Ecology for the twentyfirst century. (Org. George Sessions) Boston, Londres: Shambhala, p. 213-221, 1995.

. The shallow and the deep, long-range ecology movement: a summary. In: The deep ecology movement: an introductory anthology. (Orgs. Alan Drengson e Yuichi Inoue) Berkeley, California: North Atlantic Books, p. 3-9, 1995.

OLIVEIRA, Fábio Corrêa Souza de. Categorias dos direitos humanos aplicadas aos direitos dos animais não-humanos. Tese aprovada e apresentada na I World Conference on Bioethics and Animal Rights. Universidade Federal da Bahia (UFBA), 2008.

Direito dos Animais. In: Função social do Direito Ambiental. Rio de Janeiro: Campus, p. 324-347, 2009.

Direitos humanos e direitos não-humanos. In: Direito público e evolução social. Rio de Janeiro: Lumen Juris, 2011.

Especismo religioso. In: Revista Brasileira de Direito Animal, n. 8. Salvador: Evolução, p. 161-220, 2011.

REGAN, Tom. The case for animal rights. University of California, 2008. SINGER, Peter. Libertação animal. Tradução por Marly Winckler. Porto Alegre: Lugano, 2004 . 